\title{
CONSTRUÇÕES NORMATIVAS NA CIDADE STANDARD: VULNERABILIDADES E SUSTENTABILIDADE
}

RosÂngela LunardelLI CaVallazZI

Advogada, Professora Adjunto do Programa de Pós-Graduação em Urbanismo da Faculdade de Arquitetura e Urbanismo da Universidade Federal do Rio de Janeiro e do Programa de Pós-Graduação em Direito da Pontifícia Universidade Católica do Rio de Janeiro.

Denise Barcellos Pinheiro Machado

Arquiteta e Urbanista. Professora Titular da Faculdade de Arquitetura e Urbanismo e do Programa de Pós-Graduação em Urbanismo da Faculdade de Arquitetura e Urbanismo da Universidade Federal do Rio de Janeiro.

\section{Resumo}

A dimensão do atual processo de globalização acaba gerando novas vulnerabilidades, tanto sociais como ambientais, questionando de forma incisiva as perspectivas da sustentabilidade nas cidades contemporâneas. Na perspectiva da eficácia social da norma urbanística o presente estudo estabelece o diálogo entre os campos Direito e do Urbanismo. O Direito à cidade é um conceito chave, estruturante da justiça distributiva e está diretamente associado à qualidade de vida dos habitantes da cidade. A natureza dos direitos que estruturam o Direito à cidade, a exemplo dos direitos do consumidor e do meio ambiente é a sua titularidade indefinida, tratando-se de direitos coletivos e difusos.

\section{Palavras-chave}

Cidade standard; Vulnerabilidade; Sustentabilidade; Eficácia social da norma; Direito à cidade.

\section{Resumen}

La dimensión del actual proceso de globalización acaba generando nuevas vulnerabilidades, tanto sociales como ambientales, cuestionando de forma incisiva las perspectivas de la sustentabilidad en las ciudades contemporáneas. En la perspectiva de la eficacia social de la norma urbanística el presente estudio establece el dialogo entre los campos del derecho y del urbanismo. El Derecho a la ciudad es un concepto clave, estructurados de la 
justicia distributiva y está directamente asociado a la calidad de vida de los habitantes de la ciudad. La naturaleza de los derechos que estructuran el Derecho a la ciudad, a ejemplo de los derechos del consumidor y del medio ambiente es su titularidad indefinida, se tratando de derechos colectivos y difusos.

\section{Palabras clave}

Ciudad standard; Vulnerabilidad; Sustentabilidad; Eficacia social de la norma; Derecho a la ciudad.

\section{Introdução}

O Direito à Cidade ${ }^{1}$ é um conceito chave, estruturante da justiça distributiva e está diretamente associado à qualidade de vida dos habitantes da cidade.

Não são direitos individuais que estarão lado a lado, isoladamente, segundo a lógica dos direitos individuais. Com o status de direito coletivo estarão devidamente articulados, imbricados, constituindo um outro lugar, um outro momento do próprio direito à cidade. Feixe de direitos que em virtude da sua articulação redimensiona a capacidade de eficácia social da norma.

A concepção inovadora do projeto urbana está fundada nos atores, nas escalas e nas temporalidades. As temporalidades não estariam restritas ao tempo da realizaçáo dos projetos, mas também a que diz respeito à concepção e definiçóes conceituais, dinâmica dos atores no processo, incluindo acordos, financiamentos, exigências administrativas e burocráticas.

Segundo Yanis Tsiomis (2006, p. 78) a cidade constitui uma rede simbólica sancionada onde se combinam relações variáveis de componentes imaginários ou simbólicos com componentes concretos. Assim o projeto urbano qualifica o espaço.

A dimensão tempo-espaço, base dessa abordagem permitirá identificar a dinâmica inerente ao projeto urbano.

"É evidente que a extensão do projeto urbano leva a comportamentos diferentes em relação ao tempo, ao contexto e aos atores. A noção de escala não é apenas quantitativa, mas também qualitativa. Conforme a escala, trabalha-se diferentemente com as ferramentas

1 A Carta Mundial pelo Direito à Cidade formulada por entidades participantes do I Fórum Social Mundial em 2001, bem expressa essa noção: "O Direito à Cidade é interligado e interdependente a todos os direitos humanos internacionalmente reconhecidos, concebidos integralmente. Inclui, portanto, os direitos à terra, aos meios de subsistência, ao trabalho, à saúde, à educação, à cultura, à moradia, à proteção social, à segurança, ao meio ambiente sadio, ao saneamento, ao transporte público, ao lazer e à informaçấo. Inclui também (...) a garantia da preservação da herança histórica e cultural”. 
e também com a démarche. Tudo muda com a escala: atores, temporalidades, escalas métricas, técnicas, financiamentos, fases de realização; E o projeto é um exercício sobre as articulaçôes, os encontros entre diferentes situações, às leituras específicas e os métodos aplicados, e também sobre as escalas que ele deve enfrentar. Trata-se, portanto, de um trabalho sobre as articulaçóes entre entidades funcionais, espaciais e as escalas funcionais, sobre a articulação de diferentes abordagens próprias aos campos do conhecimento e das disciplinas que tratam do espaço de todas estas formas. Metodologicamente, devem-se articular os conhecimentos sobre o contexto, as situaçóes que prevalecem e o desenho" (TSIOMIS, 2003, p. 290).

$\mathrm{Na}$ mesma perspectiva $\mathrm{O}$ caráter estratégico do projeto urbano acontece em duas vias. Além do seu já reconhecido papel estratégico na formulação de planos e políticas públicas, tanto no que se refere ao seu potencial transformador do espaço, como na visibilidade que confere à cidade e aos poderes públicos.

O projeto urbano pode ser definido por sua diversidade de escalas e, como lembram Guy Debord e Henri Lefebvre (1996, 2004), por seu teor técnico e político.

O presente estudo considera relevante explicitar a relação entre o agravamento das vulnerabilidades dos sujeitos, das relaçóes e dos espaços que questionam de forma incisiva as perspectivas da sustentabilidade nas cidades contemporâneas.

Com certeza náo deve parecer novidade articular o tema da sustentabilidade com o da vulnerabilidade, aliás, eles constituem temas conexos, pois o senso comum, em via de regra, justifica a necessária sustentabilidade justamente em razão dos riscos inerentes que o planeta vem sofrendo especialmente na sociedade de consumo, a raiz do processo de globalização. Contudo, sem reconhecer ou explicitar esta linha direta entre a lógica uniformizadora da sociedade de consumo, hoje especialmente a de serviços, com a desarticulação entre o homem e o ambiente de seu entorno, neste caso, ressaltamos particularmente, a paisagem.

\section{O Atual Processo de Globalização na Cidade Standard}

A dimensão do atual processo de globalização acaba gerando novas vulnerabilidades, tanto sociais como ambientais, logo a relevância em contextualizar situaçóes e sujeitos vulneráveis.

Jorge Riechmann (2000, p. 216), señala que "el orden económico internacional globalizado, lejos de mitigar las desigualdades sociales y los desequilibrios ambientales profundiza la brecha...".

Mas, se parece fácil estabelecer este necessário dialogo entre os contextos, relaçóes e sujeitos vulneráveis, com o tema de sustentabilidade não se pode dizer o mesmo em 
relação ao conteúdo do conceito de sustentabilidade que mesmo podendo ser considerado um conceito aberto ou com textura aberta, dificulta ainda mais o já complexo processo de interpretação.

A suposta imprecisão do conceito sustentabilidade sugere que não exista como é bem razoável, uma hegemonia de discurso. Conforme Henri Acselrad (1999, p. 80), o discurso econômico foi, sem dúvidas, o que melhor se apropriou do conceito de sustentabilidade.

Sobre possíveis consensos, considerando também os conceitos de risco, incerteza e vulnerabilidade o desafio neste diálogo entre os campos do Urbanismo e do Direito entendendo que a dimensão do atual processo de globalização. Em sentido inverso, acaba gerando novas vulnerabilidades, tanto sociais como ambientais.

Milton Santos contextualiza a paisagem mercadoria, como objeto de consumo: "Há um verdadeiro retrocesso quanto à noção de bem público e de solidariedade, do qual é emblemático o encolhimento das funçóes sociais e políticas do Estado com a ampliaçáo da pobreza e os crescentes agravos à soberania, enquanto se amplia o papel político das empresas na regulação da vida social” (2000, p. 38).

Este processo gera espacialização dos riscos urbanos e fragilizam os direitos que compóem o direito à cidade. Neste sentido, a globalização é fragmentação (SANTOS, 2009).

A globalização - confusa e perversa - não é irreversível, ou melhor é passível de reversibilidade ao ser humanizada.

Dessa afirmação não se deve concluir que estaríamos diante de um processo inexoravelmente imposto pela dinâmica da sociedade de mercado, ao contrário, a capacidade de resistência e principalmente de invenção e de produção de novas relações das práticas sociais instituintes constitui, segundo nossa concepção, a grande possibilidade no sentido da eficácia social da norma. Em outras palavras, o filtro humano na nova ética do consumo (BAUDRILARD, 2000, pp. 168-170).

O único contraponto a este processo, ou seja, o único espaço que ainda mantém unidade e identidade, ou seja, o das práticas sociais.

A paisagem urbana como mercadoria está no plano global, obstáculo que é da proteção do patrimônio cultural. Enquanto a paisagem urbana como humanização ${ }^{2}$ do meio

2 Cultura no sentido de humanização da natureza encontramos em Cosgrove, "Paisagem não é meramente o mundo que vemos, é a construção, a composição do mundo. Paisagem é uma maneira de ver o mundo”.0 ("Landscape is not merely the world we see, it is a construction, a composition of that world. Landscape is a way of seeing the world") COSGROVE, Denis E. Social Formation and Symbolic Landscape. Wisconsin: Wisconsin Press, 1998. pp.13-14. Já em Marilena Chauí encontramos:“Cultura é, pois, a maneira pela qual os humanos se humanizam e, pelo trabalho, desnaturalizam a natureza por meio de práticas que criam a existência social, econômica, política, religiosa, intelectual e artística”em Chauí, Marilena, Cidadania Cultural, 1a ed. São Paulo: Editora Fundação Perseu Abramo, 2006, p. 114. 
ambiente natural, está no plano local, possibilidade que é da proteção do patrimônio cultural.

A cidade contemporânea, situada na sociedade de consumo e mercado é vista pelos setores econômicos e em certa medidas pelos poderes públicos, cada vez como uma cidade estandardizada ${ }^{3}$. Entretanto a complexidade da cidade contemporânea lhe confere o caráter plural e de fragmentação.

O competente processo de uniformização fruto do processo de sistematização e codificação oriundos dos tempos modernos, se adéquam à dinâmica do processo de globalização. Ultrapassando fronteiras, traz como marca não só a falácia da unidade, mas principalmente mantém um pressuposto árduo no que tange as possibilidades do reconhecimento das diferenças e da sociedade plural e a exigência da uniformização dos sentidos.

A sociedade contemporânea é reconhecida como uma sociedade de risco e contemporaneamente, na sociedade de serviços (CALAIS-AULOY, 1992, p. 155), que emerge da acumulação flexível (HARVEY, 2000), novas formas de vulnerabilidade atingem o cidadão. Os graves efeitos do processo de globalização que instauram flexibilidade e precariedade na relação laboral se somam à inserção também na sociedade de consumo.

A insegurança e a urgência das novas intervençóes criam um cenário de vulnerabilidade simbólica que pode ser a chave de entendimento do urbanismo atual. Entender esta complexidade é urgente, pois nos projetos de cidade que se configuram cada vez menos parece haver espaço para o exercício da diferença.

Do reconhecimento desta vulnerabilidade, seja ela jurídica ou científica, fática, científica ou sócio-econômica e informacional (MARQUES, 2002) advém a necessidade de uma proteção especial. A sociedade contemporânea de risco sofre os efeitos do processo de globalização com a uniformização de tudo e de todos e também enfrenta as tensóes fruto das exigências do mercado, da incerteza, das rupturas dos princípios e tradiçóes.

Enfrentar o tema da sustentabilidade requer, portanto, sempre um olhar prudente sobre o contexto, uma cautela necessária para manter o espírito cientifico em alerta.

Segundo esta lógica, se assim podemos dizer, buscamos situar e contextualizar o tema na sociedade contemporânea no caldeirão da cidade standard e suas imbricadas vulnerabilidades.

3 Sobre conceito de cidade standard vide CAVALLAZZI, Rosângela Lunardelli In Relatório de Pesquisa projeto Códigos da cidade: análise das interferências jurídico-urbanísticas na cidade standard, FAPERJ/ PROURB - PUC-Rio, Rio de Janeiro, 2012.

Entende-se cidade-standard na lógica do mercado mergulhada em condiçöes de vulnerabilidade crescente realizada a partir da precarização do trabalho e que se concretiza na produção de seu espaço. 
Sendo a sociedade contemporânea caracterizada pela ampla desigualdade e pelas inúmeras vulnerabilidades, tende a aumentar os espaços vulneráveis, os sujeitos vulneráveis e as relações vulneráveis.

$\mathrm{Na}$ cidade standard o habitante, portanto, adere a uma cidade que não permite diálogo, e sua sobrevivência cada vez mais se constitui em espaços de desigualdade. E na paisagem da cidade standard a uniformização predomina sobre a história produzida pelos seus moradores ${ }^{4}$.

Ou seja, a dimensão social pode estar representada pela estandardização da cultura, do consumo, e inclusive da economia local (MUNOZ, 2008, p. 12). O fato com certeza não constitui em si uma novidade, pois a matriz moderna (adotada tanto no campo jurídico, quanto no campo do urbanismo) foi sempre muito competente na produção de falsas igualdades 5 .

A cidade standard, padronizada e pretensamente homogeneizada vem sendo moldada por movimentos aparentemente contraditórios. Parece estranho, para não dizer um contrassenso, mas é possível reconhecer nas cidades standard dois movimentos simultâneos: a fragmentação e a uniformização.

A uniformização em outra escala ou face tem sido também uma estratégia/ instrumento competente para padronizar, estandardizar as cidades no "mundo" globalizado. Portanto quando trabalhamos o conceito de cidades standard estamos reconhecendo este padrão uniformizador, uma realidade sem identidade.

A fragmentação é uma das características mais fortes das cidades atuais, perpassa o urbanismo, as questóes sociais e culturais. Em que pese as diferentes escalas administrativas, a cidade hoje é formada por um somatório de várias cidades, que no território podem ser compartilháveis segundo questôes em comum. Mas há também o oposto: a cidade que pertence a um determinado território administrativamente, mas sua comunidade náo possui o sentimento de pertencimento da figura representativa que está inserida.

$\mathrm{O}$ interprete da cidade deve enfrentar nas suas reflexóes o impacto inexorável que o processo de globalização impóe, especialmente, no que tange à uniformização pretendida e alcançada pela sociedade de mercado.

Ocorre na realidade contemporânea um efeito de fragmentação, a exemplo da lógica pós-moderna, das políticas de planejamento e de urbanismo no sentido inverso da proteção

4 "En términos de paisaje urbano, es cada vez más común encontrar similitudes y paisajes estandarizados en ciudades completamente diferentes, con historias, cultura, población nada comunes. Es decir, se tiene la misma impresión en diferentes centro históricos o frentes maritimos en cualquier ciudad". Vide MUNOZ, Francesc, Urbanalización: paisajes comunes, lugares globales, Barcelona, Gustavo Gili, 2008, pp. 12 e ss.

5 Ver, por exemplo, BOBBIO, Norberto. A era dos Direitos. Tradução de Carlos Nelson Coutinho. Nova edição. Rio de Janeiro: Elsevier, 2004. 
do patrimônio cultural, quando, por exemplo, às esferas municipal, estadual e federal sobrepóem projetos, ações e omissóes, ressaltando lacunas mutuamente.

A fragmentação, portanto, tem sido reconhecida como código próprio do movimento de globalizaçáo. Constitui também estratégia, pois as partes deslocadas do todo perdem o sentido.

Assim acontece, por exemplo, no caso dos direitos sociais que compóem o Direito à cidade. Evidentemente que a efetividade de um desses direitos é importante e de imediato indica tutela jurídica, entretanto, a realização do Direito à cidade somente ocorre quando, articuladamente, todos os direitos sociais que constituem o feixe de direitos sáo efetivados.

A fragmentação da norma e da forma, no contexto da globalização, conforme o senso comum reconhece, desmantela unidades, alcança não apenas o âmbito econômico, mas principalmente os âmbitos político e social. Este processo gera espacialização dos riscos urbanos e fragilizam os direitos que compóem o Direito à cidade.

No processo de fragmentação da norma ocorre, necessariamente, uma espacialização, uma ocupação e registro no espaço simbólico do campo jurídico e, simultaneamente, a cristalização de uma nova forma no espaço da cidade. Estabelece-se assim, provavelmente, uma concorrência entre o direito codificado, uniformizador de sentidos, de conteúdos normativos, e o pluralismo intrínseco das práticas sociais instituintes.

Concretamente a fragmentação lança luz na pluralidade, permitindo em um segundo momento a recomposiçáo com o consenso ampliando a dimensão da eficácia social da norma urbanística.

Assim o fenômeno da fragmentação, independentemente de seus efeitos dispersores de direitos e segregador de espaços, pela via da mudança do seu eixo do mercado para o homem, da forma, para o conteúdo, poderá dar visibilidade a novos direitos, novas demandas, construir outros espaços a partir de construçóes normativas na cidade standard.

Logo a importância da eficácia social da norma urbanística ${ }^{6}$, ou seja, tornar exequível o conteúdo normativo segundo critérios da finalidade, incidência e legitimidade.

Segundo Yanis Tsiomis a cidade constitui uma rede simbólica sancionada onde se combinam relações variáveis de componentes imaginários ou simbólicos com componentes concretos. Assim o projeto urbano qualifica o espaço.

6 Vide sobre a eficácia social da norma urbanística CAVALLAZZI, Rosangela Lunardelli. "O estatuto epistemológico do Direito Urbanístico Brasileiro: possibilidades e obstáculos na tutela do Direito à Cidade”. In: COUTINHO, R.; BONIZZATO, L. (Org.). Direito da cidade: novas concepçóes sobre as relaçóes jurídicas no espaço social urbano. Rio de Janeiro: Lumen Juris, 2007, pp. 53-69. 
Privilegiar o conceito de cidade visa não só reconhecer e ampliar a abordagem interdisciplinar, mas, principalmente, ganhar um novo olhar, uma nova perspectiva na leitura das relaçóes sociais contemporâneas

O reconhecimento do conflito permanente e da pluralidade é o único caminho, pressuposto mesmo da identificação da vulnerabilidade social, com outras palavras a possibilidade das condiçóes da democracia, do dissenso.

No processo de globalização onde novas vulnerabilidades surgem o Direito volta a ter papel principal na construção da cidadania e da sustentabilidade

A dimensão do atual processo de globalização acaba gerando novas vulnerabilidades, tanto sociais como ambientais questionando de forma incisiva as perspectivas da sustentabilidade nas cidades contemporâneas.

A realidade brasileira remete para um contínuo de possibilidades e obstáculos. As questóes urbanas totalmente matizadas pelo processo contínuo de pobreza, conforme Simon Schwartzman (2004) são inúmeras e graves, mas ao mesmo tempo as praticas sociais, têm conseguido direcionar políticas públicas que reconhecem a grave realidade e avançam, não na medida desejável, mas no caminho de diálogos possíveis.

\section{Conclusões}

O presente estudo considera relevante explicitar a relação entre o agravamento das vulnerabilidades dos sujeitos, das relaçóes e dos espaços que questionam de forma incisiva as perspectivas da sustentabilidade nas cidades contemporâneas.

A dimensão do atual processo de globalização acaba gerando novas vulnerabilidades, tanto sociais como ambientais, questionando de forma incisiva as perspectivas da sustentabilidade nas cidades contemporâneas. Na perspectiva da eficácia social da norma urbanística o presente estudo estabelece o diálogo entre os campos Direito e do Urbanismo. O Direito à cidade é um conceito chave, estruturante da justiça distributiva e está diretamente associado à qualidade de vida dos habitantes da cidade. A natureza dos direitos que estruturam o Direito à cidade, a exemplo dos direitos do consumidor e do meio ambiente é a sua titularidade indefinida, tratando-se de direitos coletivos e difusos.

As dimensões ambiental, fundiária, urbanística, regional e político-institucional precisam ler levadas em consideração. Sendo assim, as dinâmicas ambientais participam do processo de desenvolvimento urbano e regional como elementos fundamentais.

A cidade como criação coletiva, plural, tem por exigência a necessária tradução jurídico-urbanística de seus instrumentos. Cabe aos urbanistas e juristas utilizarem sua sensibilidade privilegiada para perceber os significados desta tradução para depois devolvê-los 
à população, de forma diversificada, fundindo objetos e normas, de acordo com as necessidades da população. Traduzindo na perspectiva da eficácia social da norma urbanística, estaríamos falando do critério da legitimidade ${ }^{7}$.

Portanto, as interferências jurídico-urbanísticas na cidade standard poderão, ao mesmo tempo, gerar novas reflexões e novas soluçóes na direção de retomar um caminho para a reconfiguração do direito à cidade como ponto de chegada da reprodução do espaço urbano.

\section{Referências}

ACSERALD, H. Vulnerabilidade ambiental, processos e relaçóes. In: Rede Brasileira de Justiça Ambiental, 1999. Recuperado dia 10 de agosto de 2013, de <http://www. justicaambiental.org.br/_justicaambiental/pagina.php?id=497>.

BAUDELAIRE, C.; RUSKIN, J.; KERN, D. Paisagem Moderna: Baudelaire e Ruskin, John. Introdução, traduçáo e notas. Porto Alegre: Editora Sulina, 2010.

BAUDRILlarD, J. O Sistema dos Objetos. São Paulo: Perspectiva, 2000.

BAUDRILLARD, J. Senhas. Tradução de Maria Helena Kuhner, Rio de Janeiro: DIFEL, 2001.

BOBBIO, N. A era dos Direitos. Tradução de Carlos Nelson Coutinho. Rio de Janeiro: Elsevier, 2004.

BOLTANSKI, L.; CHIAPELLO, E. O novo espírito do capitalismo. Tradução de Ivone C. Benedetti. São Paulo: WMF Martins Fontes, 2009.

BONIZZATO, L. (Org.). Direito da cidade: novas concepçóes sobre as relaçóes jurídicas no espaço social urbano. Rio de Janeiro: Lúmen Júris, 2007.

BORJA, J.; MUXI, Z. El espacio público: ciudad y ciudadania. Barcelona: Edición Electa Disputació Barcelona Xarxa de municipis, 2003.

BOURDIEU, P. O poder simbólico. Rio de Janeiro: Bertrand Brasil, 2007.

BOURGOIS. J. Solidarité Et Urbanirme In, La Loi SRU Et Le Droit De L'urbanisme. Paris: Litec Groupe Lexis Nexis, 2002.

CALAIS-AULOY, J., Droit de consommation, 3. ed, Paris : Dalloz, 1992.

CAVALLAZZI, R. L.; RIBEIRO, C. R. Paisagem urbana e direito à cidade. Coleção Direito e Urbanismo. Vol. 1. Rio de Janeiro: Editora Prourb, 2010.

7 Refere-se aos critérios para o estudo da eficácia social da norma urbanística: finalidade, incidência e legitimidade. 
CAVAllaZZI, R. L. Plasticidade do Plano Contratual. Rio de Janeiro. Tese (Doutorado em Direito) - Faculdade de Direito, Universidade Federal do Rio de Janeiro, Rio de Janeiro, 1993.

CAVAllaZZI, R. L. Perspectivas Contemporâneas do Patrimônio Cultural. Paisagem Urbana e Tombamento. In: FERNANDES, E.; ALFONSIN, B. (coords) Revisitando o Instituto do Tombamento. Belo Horizonte: Editora Fórum, 2010.

CAVALLAZZI, Rosângela Lunardelli In Relatório de Pesquisa projeto Códigos da cidade: análise das interferências jurídico-urbanísticas na cidade standard, FAPERJ/ PROURB - PUC-Rio, Rio de Janeiro, 2012.

CAVALLAZZI, R. L.; RIBEIRO, C. R. Entre dois morros: disputa simbólica na paisagem urbana carioca. ANAIS do SICYURB. Lisboa. 2011.

CAVAllaZZI, R. L. In Relatório de Pesquisa projeto Códigos da cidade: análise das interferências jurídico-urbanísticas na cidade standard, FAPERJ/PROURB - PUC -Rio, Rio de Janeiro, 2012.

CAVALLAZZI, R. L.. O estatuto epistemológico do Direito Urbanístico Brasileiro: possibilidades e obstáculos na tutela do Direito à Cidade. In: COUTINHO, R.; BONIZZATO, L. (Org.). Direito da cidade: novas concepçôes sobre as relaçôes jurídicas no espaço social urbano. Rio de Janeiro: Lumen Juris, 2007, pp. 53-69.

CAVALLAZZI, R. L. Urbanismo e direito: notas para uma abordagem interdisciplinar do espaço urbano. In: MACHADO, Denise B. Pinheiro. (Org.). In: Seminario de história da cidade e do urbanismo IV. Rio de Janeiro, 1996. Anais UFRJ/Prourb, 1996. V. 2, p. 882-887.

CAVALLAZZI, R. L. Novas Fronteiras do Direito Urbanístico In: TEPEDINO, G.; FACHIN, L. E. (Orgs) O Direito e o tempo embates jurídicos e utopias contemporâneas - Estudos em homenagem ao Professor Ricardo Pereira Lira. Rio de Janeiro. Renovar, 2008. pp. 683-709.

CAVALLAZZI. R.L. O estatuto epistemológico do direito urbanístico brasileiro. In: COUTINHO, R.; BONIZATO, L. (Org.) Direito da cidade: novas concepçóes sobre relaçóes jurídicas no espaço social urbano. Rio de Janeiro: Lumen Juris, 2007.

CHARLES, H. Droit de L'urbanisme. Paris: PUF, 1997.

CHAUÍ, M. Cidadania Cultural, São Paulo: Editora Fundação Perseu Abramo, 2006.

COSGROVE, D. E. Social Formation and Symbolic Landscape, Wisconsin: Wisconsin Press, 1998.

DALlARI, A. A.; FERRAZ, S. Estatuto da Cidade. São Paulo: Editora Max Limonad, 1999. 
DEBORD, G. A sociedade do espetáculo. Rio de Janeiro: Contraponto, 1997.

FERNANDES, E.; ALFONSIN, B. (Orgs.) A lei e a ilegalidade na produçáo do espaço urbano. Belo Horizonte: Del Rey, 2003.

FERNANDES, E. Direito Urbanístico. Del Rey, Belo Horizonte,1999.

HARVEY, D. O engima do capital e as crises do capitalismo. Lisboa: Bizâncio, 2011.

HARVEY, D.; SMITH, N. Capital financiero, propiedad inmobiliaria y cultura. Bellaterra: Servei de Publicacions de la Universitat Autònoma de Barcelona, 2005.

HOBSBAWM, E. A era das revoluçóes: 1789-1848. São Paulo: Paz e Terra, 2009.

HOBSBAWN, E. O novo século: entrevista a Antonio Polito. São Paulo: Companhia das letras, 2009.

LEBRETON, J. P. (Dir.). Etat de droit et urbanisme. Les Cahiers du Gridauh: Editions du Moniteur, no. 11, 2004.

LEFÈBVRE, H. O Direito à Cidade. 3. ed., São Paulo, Centauro, 2004.

LIRA, R. P. Elementos de direito urbanístico. Rio de Janeiro: Renovar, 1997.

LOURES, Moema F. O projeto no espaço urbano: riscos da paisagem. In: CAVALLAZZI, R. L.; RIBEIRO, C.R. Paisagem urbana e direito à cidade. Coleçáo Direito e Urbanismo. Rio de Janeiro: Editora PROURB, V. 1. 2010.

MACHADO, D. B. P. Tipo e Urbanismo: Novas espacialidades no Século XX. Porto Alegre: Marcavisual, 2009.

MACHADO, P. A. L. Direito Ambiental Brasileiro. São Paulo, Malheiros, 1998.

MARICATO, E. O impasse da política urbana no Brasil. Petrópolis, RJ: Vozes, 2011.

MARQUES, C. L. Contratos no Código de Defesa do Consumidor: o novo regime das relaçóes contratuais. 5. ed. Rev., atual. e ampl. São Paulo: Editora Revista dos Tribunais, 2002.

MARQUES, C. L. Contratos no Código de Defesa do Consumidor. São Paulo: Editora Revista dos Tribunais, 2005.

MATTOS, L. P. (Org.). Estatuto da Cidade Comentado. Belo Horizonte: Mandamentos, 2002.

ORIANNE, P. Dictionnaire encyclopédique de theórie et de sociologie Du droit, Paris: L.G.D.J, 1993.

RIECHMANN, J. Un mundo vulnerable, Madrid: Libros de Catarata, 2000.

ROLNIK, R. A Cidade e a Lei. Legislação, Política Urbana e Territórios na Cidade de Sáo Paulo. São Paulo: FAPESP, Studio Nobel, 2000. 
ROPPO, E. O Contrato. Coimbra: Livraria Almedina, 1988.

SANTOS, B. S. A Crítica da Razáo Indolente: contra o desperdício da experiência. Vol. 1. São Paulo: Cortez, 2001.

SANTOS, M. A natureza do Espaço: técnica e tempo - razão e emoção. São Paulo: Hucitec, 2009.

SANTOS, M. Por uma outra Globalizaçáo: do pensamento único à consciência universal. Rio de Janeiro: Record, 2000.

SANTOS, M. Técnica, Espaço e Tempo: Globalização e meio técnico-científico informacional. 2a ed. São Paulo: Hucitec, 1996.

SCHWARTZMAN, S. As causas da pobreza. Rio de Janeiro: Editora FGV, 2004.

SILVA, J. A. Direito urbanístico brasileiro. São Paulo: Malheiros, 1995.

TSIOMIS, Y. (Org.). Au Coeur du Projet Urbain. Paris: Eds. De L'Imprimeur, 2006.

TSIOMIS, Y. Por ocasião da operação do Grand Paris. O projeto metropolitano: uma improvisação erudita. In: CAVALLAZZI, R. L.; PARAIZO, R. C. (Org.). Patrimônio, ambiente e sociedade: Novos desafios espaciais. Rio de Janeiro: PROURB, 2012.

TSIOMIS, Y. O projeto urbano hoje: entre situaçôes e tensões. Tradução de Denise B. Pinheiro Machado. In. MACHADO, D. B. P.; PEREIRA, M. d. S.; SILVA, R. C. M. (Orgs). Urbanismo em questáo. Rio de Janeiro: UFRJ/PROURB, 2003.

WOLKMER, A. C. Introdução ao Pensamento Jurídico Crítico. São Paulo: Saraiva, 2006. 